\title{
Un ejemplo de mundialización: El movimiento de biombos desde el Pacífico hasta el Atlántico (s. XVII-XVIII)/
}

\author{
A case of globalization: the circulation of folding screens \\ from the Pacific to the Atlantic (17th-18th centuries)
}

\section{Alberto Baena Zapatero}

Centro de História de Além-Mar

(Universidade Nova de Lisboa), Portugal

El artículo analiza la circulación de objetos entre Asia, América y Europa a través de un estudio de caso: la producción y comercio de biombos. El análisis de las redes económicas asociadas al tráfico de obras de arte supera los límites nacionales o imperiales y nos obliga a romper con los planteamientos tradicionales de centro y periferia. Asimismo, las relaciones personales que implicó el proceso de encomienda de biombos o la difusión de estos objetos a través del movimiento de personas por cuatro continentes, muestran cómo el desarrollo de la economía mundial o la formación de imperios de dimensiones planetarias incentivó los intercambios en todos los niveles y dio como resultado el nacimiento de una nueva cultura material de carácter mundial.

PAlabRas ClaVE: Biombos; Comercio; Mundialización; Globalización.

This article analyzes the circulation of goods between Asia, America, and Europe employing a case-study perspective: the manufacturing and commerce of folding screens. Study of the economic networks related to art trade overcomes national or imperial boundaries and calls for a breakdown of conventional centre-periphery schemes. This article therefore studies personal relationships in the commission of screens and in the diffusion of the finished goods through a survey of the movements of people in four continents. My main aim is to show that the development of a world-economy and the formation of world-scale empires fostered exchanges of all kinds and resulted in a new material culture of a truly global character.

KEYwORDS: Folding screens; Commerce; Globalization. 


\section{Introducción}

La conquista de América y el desarrollo de nuevas rutas directas con Asia, abren un campo de estudio que abarca cuatro continentes y las principales civilizaciones de la Edad Moderna. Las transformaciones que sufrió el mundo durante este periodo nos invitan a preguntarnos hasta qué punto muchos de los fenómenos asociados a la globalización son recientes o si, por el contrario, cuentan con antecedentes que es necesario revisar. ${ }^{1}$ En este sentido, los biombos suponen la excusa perfecta para indagar en lo que Sanjay Subrahmanyam definió como connected histories, las relaciones históricas que se dieron entre sociedades contemporáneas, y tratar de evaluar las implicaciones culturales y sociales que propiciaron los nuevos caminos iniciados por portugueses y españoles. ${ }^{2}$

La importancia de considerar los biombos como un producto más inserto en el comercio internacional resulta evidente si tenemos en cuenta el hecho de que hasta el momento existen pocas investigaciones que se hayan ocupado detenidamente de la producción, transporte y venta de estos muebles, dedicando la mayoría del esfuerzo a los textiles o la porcelana. Algunos trabajos de historiadores norteamericanos y portugueses han examinado los biombos dentro del conjunto del arte namban en Japón, sin embargo, se ha prestado poco interés a la producción china de estas piezas destinadas a la exportación. Además, abundan en los catálogos de exposiciones análisis particulares sobre los principales ejemplares conservados hasta la fecha, que se limitan a describirlos desde un punto de vista estético (iconografía, estilo, símbolos, materiales...), poniendo poca atención en su significado histórico y desligando de manera artificial el nacimiento de una nueva economía mundial de sus manifestaciones artísticas.

Para el caso de Nueva España, tan sólo el libro de Teresa Castelló y Marita Martínez publicado hace cuarenta años o, más recientemente, los estudios de Gustavo Curiel, Santiago Sebastián y Sofía Sanabrais, le conceden una consideración pormenorizada a este asunto. ${ }^{3}$ No obstante, estos autores se fijan fundamentalmente en los biombos de factura mexicana, dejando de lado el tráfico de este tipo de muebles desde su origen en Asia hasta América o Europa.

1 Sobre el movimiento de personas, objetos e ideas en la Edad Moderna: Gruzinski, 2010; Russell Wood, 1998.

2 Subrahmanyam, 1993 y 1997, 735-762.

3 Castelló, 1970; Sanabrais, 2006, 69-106; Sebastián, 1992; Curiel, 1999, 9-32. 
En cuanto al otro gran virreinato americano, es importante señalar que hay pocos trabajos que traten del mobiliario en Perú durante este periodo $\mathrm{y}$, en aquellos con los que contamos, apenas se encuentra alguna referencia a la existencia de biombos en las casas principales. ${ }^{4}$ No obstante, a tenor de la abundancia de estas piezas detectada en la investigación realizada en los protocolos notariales de la ciudad de Lima durante el siglo XVIII, consideramos de la mayor importancia recuperar su presencia en los ajuares domésticos, ya que amplían considerablemente el marco geográfico que hasta ahora se ha manejado.

Además, siendo el estudio artístico de estos objetos de una gran relevancia, nos proponemos un examen más detallado de esta fuente desde un enfoque tanto económico, que incluya esta mercancía en el conjunto del tráfico mundial de objetos de lujo, como social, poniendo de manifiesto los motivos del éxito de estos muebles en los salones de tres continentes. En este sentido, los biombos constituyen un buen ejemplo de la necesidad de observar los fenómenos históricos no sólo desde una perspectiva más amplia sino, además, interdisciplinar y transversal. Asimismo, las redes personales que implicó el proceso de encomienda de obras de arte o la difusión de los biombos por medio del movimiento mundial de personas, pueden mostrar cómo la extensión del tráfico comercial o la formación de imperios de dimensiones planetarias incentivaron los intercambios en todos los niveles, dando como resultado el nacimiento de una nueva cultura material de la que los biombos constituyen una de sus mejores expresiones.

Por último, resulta necesario subrayar las dificultades que implica el estudio del comercio internacional de biombos, ya que su tránsito abarcaba un amplio espectro geográfico y se trataba de una mercancía minoritaria en los cargamentos. Normalmente es difícil cuantificar los productos inmersos en el trato transpacífico porque en los registros de mercancías sólo se solían computar los cajones o fardos que se llevaban, sin especificar su contenido, y una gran parte de los intercambios se realizaron de manera clandestina y no dejaron ninguna pista. Por lo tanto, la información con la que contamos no nos permite establecer series anuales de exportación de biombos o estudiar la evolución de sus precios. No obstante, contamos con varias fuentes indirectas que transmiten valiosas informaciones con las que cubrir estas lagunas: crónicas, libros de sobordo, registros de aduanas, los propios biombos conservados y, sobre todo, los inventarios de

4 Crespo, 2006 y Germaná, 2008, 189-206. 
bienes de los territorios implicados en el comercio, que conservan la evidencia de estas relaciones. Así, aportaremos datos de diferente naturaleza y cronología con el propósito de demostrar el éxito constante de esta mercancía en el tráfico transoceánico, su progresiva inclusión en la producción local americana y su posterior exportación a Europa.

\section{El tráfico de obras de arte a partir de los biombos}

\section{El comercio internacional en Manila}

Durante la Edad Moderna se consolidaron dos rutas que articularon la mayoría del comercio internacional en el Pacífico. La primera de estas vías fue la que iniciaron los portugueses una vez que lograron circunnavegar África y conectar con la India, China y Japón; la segunda fue la que establecieron los castellanos a través del trato entre Manila, México y Sevilla, pero que en la práctica también se extendió desde Nueva España por el resto de América. Si bien existen numerosos testimonios que permiten rastrear la presencia de muebles en la primera de esas rutas, en esta ocasión nos vamos a referir fundamentalmente al «camino español», menos conocido en lo que se refiere a su relación con el conjunto del comercio asiático, en especial el de obras de arte.

Dentro del importante volumen de mercancías que cada año llegaban hasta Manila desde los diferentes centros productores de Asia, los biombos sólo supusieron una pequeña parte de un comercio dominado por telas, especias y porcelanas. ${ }^{5} \mathrm{Su}$ transporte en largas distancias fue realizado mediante un sistema relativamente sencillo que facilitaba su protección durante el viaje. Normalmente estas piezas se introducían plegadas dentro de cajones que, en muchas ocasiones, eran elaborados especialmente para este cometido, ya que debían tener un largo mayor del habitual. Podemos hacernos una idea de cómo pudo ser el porte de estos objetos en los barcos europeos gracias a las recomendaciones que hizo Alessandro Valignano a Nunes Rodrigues sobre la forma en que debía transportar los que conduciría como regalo la embajada de japoneses. Sobre este asunto afirmaba que tenían que ser trasladados en una caja grande que él mismo había llevado para Japón y que adquirió en Cochim, debiendo ser almacenados en un local

5 Yuste, 1995, 231-264; Chaunu, 1976. 
donde «la lluvia no entrase y el agua no llegase». ${ }^{6}$ Así, no es extraño encontrar a personajes que conservaban estos recipientes para mantener en buen estado sus adquisiciones o alusiones a cajones de biombos en los registros de mercancías de los barcos, algunos incluso decorados con pintura. ${ }^{7}$

Respecto al arribo de biombos a Manila a lo largo de los siglos XVII y XVIII, es posible afirmar que generalmente pudieron hacerlo a través de cuatro tipos de intermediarios: portugueses, españoles, chinos o japoneses. La actividad realizada por los mercaderes lusos como introductores de productos asiáticos en Filipinas queda demostrada por la llegada al puerto de Manila (Cavite) de navíos con esta bandera desde Macao, Nagasaki e incluso de Goa, principales centros portugueses de redistribución en la región. A pesar de que entre las condiciones aceptadas por Felipe II en las Cortes de Tomar, al poco tiempo de proclamarse rey de Portugal, se estableció una separación administrativa y comercial entre los dos imperios, los barcos fletados en los puertos lusos llegaron con asiduidad hasta Cavite para hacer negocio. Entre 1577 y 1643 han quedado registradas 63 embarcaciones cuyo origen era Macao, además de otras siete que arribaron en 1612 y que, aunque se conoce que eran tripuladas por naturales de este reino, se ignora si procedían de Goa o de Macao. ${ }^{8}$ Para este periodo, además, no fue extraño que los barcos portugueses cargados con productos chinos se dirigiesen a Manila desde Nagasaki, consiguiendo así un trato fiscal más favorable al que recibían cuando lo hacían directamente desde Macao.

Después de la ruptura de la unión ibérica en 1640, las naves lusas continuaron llegando a Filipinas. Si bien es cierto que la guerra o el clima de hostilidad entre estos dos reinos pudieron haber afectado al comercio desde Macao, puesto que se registra un parón en la entrada de barcos desde este puerto entre 1643 y 1672, a partir de esta fecha se restablece la relación nuevamente. ${ }^{9}$ No obstante, la ausencia de barcos comandados por capitanes portugueses durante estos años no debe indicar necesariamente que quedasen al margen del comercio con Manila, ya que pudieron seguir con su actividad de manera clandestina o a través de intermediarios como

6 Canepa, 2008, 24.

7 Archivo General de Indias de Sevilla (AGI), Filipinas, 170, 4, 32r. Entre los bienes embargados al maestre de campo don Esteban Eguiño el 3 de junio de 1720 aparece «Un cajón pintado con su biobo dentro de papel nuevo».

8 Sección Contaduría de la Real Hacienda de Filipinas, AGI. Datos obtenidos a partir de la investigación realizada en el proyecto «Prosopografía de las comunidades lusófonas residentes e de passagem nas Filipinas (1582-1654)» financiado por Fundaçao para a Ciência e a Tecnologia, Portugal.

9 Chaunu, 1976, 142-169. 
los chinos, los japoneses o los armenios. Desde finales del siglo XVII, Macao deberá enfrentar la fuerte competencia de Cantón como principal plaza europea en China.

Entre los objetos que transportaron en sus bodegas los barcos de bandera portuguesa se encontraban los preciados biombos, como demuestran las crónicas que se refieren al envío de este tipo de muebles desde los puertos lusos del Pacífico hacia la India y Europa. El padre Luis Frois hizo alusión a los biombos japoneses afirmando que «ya se han mandado algunos a Portugal y a Roma, y van cada año para la India muchos», ${ }^{10}$ mientras que el padre Juan Rodríguez Tsuzu, en su Historia de la Iglesia del Japón, comenta sobre los biombos que son «cosa muy acomodada que de acá llevan para Europa, de que hay muy varios y ricos en el Fuchu». ${ }^{11}$ Entre el conjunto de productos que pasaban de Macao a Cavite también se encontró este tipo de muebles. A inicios del siglo XVII, el gobernador de Filipinas Juan de Silva envió varias veces a Macao a su criado Pedro Angulo con la misión de comprar diferentes objetos de lujo orientales, entre los que se refieren los biombos. ${ }^{12}$ Muchos de ellos fueron realizados en los talleres locales, como aconteció con el biombo del Diluvio Universal, actualmente en la colección del Museo Soumaya de la ciudad de México, o en talleres situados en otras partes de China. En este sentido, pueden considerarse una prueba de su difusión los que encontramos registrados en los inventarios de bienes de distintas ciudades de América o Europa, y a los que nos referiremos más adelante. Estos muebles no serían una excepción, ya que la relación comercial y de encargo de obras de arte a Macao desde Filipinas y Nueva España fue algo habitual. Recordemos que la reja del coro de la catedral de México fue fundida en este centro portugués por un artesano chino.

Al margen de los portugueses, los castellanos afincados en Manila siempre tuvieron un gran interés por establecer tratos comerciales directamente con los productores chinos que les permitiesen el acceso directo al lucrativo intercambio con el continente. Durante las últimas décadas del siglo XVI y primeras del XVII, la diplomacia castellana se esforzó infructuosamente por conseguir un enclave comercial estable en la costa de Fujian, similar al que disfrutaban los portugueses en Macao. Ante el fracaso de este proyecto, en parte por los esfuerzos diplomáticos lusos, los cas-

10 Fróis, 1984, 313.

11 Álvarez Taladriz, 1953, 36-37.

12 AGI, Filipinas 20, 11, 70, citado en Gil, 2011, 325-326. 
tellanos enfocaron su relación comercial en la región de Cantón. A partir de finales del siglo XVII y conforme Macao y los portugueses perdían su papel tradicional como intermediarios, esta ciudad fue cobrando importancia como centro redistribuidor de productos chinos. Resulta difícil encontrar fuentes que nos proporcionen un panorama general de las mercancías implicadas en el tráfico entre Cantón y Manila, no obstante, cuando tenemos la suerte de conservar el testimonio de los productos que transportaban los barcos castellanos, vemos que aparecen los biombos entre los cajones de sus bodegas. En el registro y descarga efectuados en 1769 a la chalupa Nuestra Señora del Carmen, que venía desde Cantón a Manila a cargo del capitán don Antonio Pacheco, encontramos «dos cajones largos sin número ni marca que contienen dentro dos beobos de maque blanco cada uno con doce hojas», valorados en 25 pesos cada uno. ${ }^{13}$

Por otra parte, las autoridades permitieron la constante llegada de población china al puerto de Cavite y su instalación permanente en un barrio de las afueras de la ciudad, el Parián, desde el que realizaban toda su actividad económica. El enorme número de sangleyes fue siempre un motivo de recelo por parte de la comunidad española y derivó en conflictos violentos. Una parte de esta población era de comerciantes pero otra estaba compuesta por trabajadores de distintos oficios. Por lo tanto, resulta difícil dictaminar si todos los biombos chinos que aparecen en los registros de bienes, tanto de México como de España, fueron producidos por artesanos afincados en el continente o si una parte de ellos no serían fabricados en los talleres de sangleyes ubicados en Manila. Como ejemplo de este problema, debemos señalar que existen diferentes teorías sobre el origen del antes citado Biombo del Diluvio. A pesar de que tradicionalmente se atribuye su producción a la escuela de Macao, otros autores como LeRoy han apuntado que pudo realizarse en Manila, elaborado por artistas asiáticos conversos al servicio de la Corona española. ${ }^{14}$ Asimismo, contamos con dos testimonios que pueden darnos una pista de la existencia de una manufactura de biombos en Manila, encuadrada seguramente en la producción de todo tipo de muebles de maque, o por lo menos de la presencia de talleres donde se remataban las piezas mandadas desde China. El primer indicio lo encontramos en el cargamento del Nuestra Señora del Carmen, donde junto a materiales para producir camapes o taburetes de maque, aparece

13 AGI, Filipinas, $942,5,145 \mathrm{v}$ y $187 \mathrm{v}$.

14 LeRoy, 1999, 119-134. 
«un cajón con cincuenta y dos hojas de loza de maque colorado para dos beobos», lo que podría indicar que se mandaban materias primas para la fabricación posterior de estos muebles. ${ }^{15}$ Asimismo, entre las propiedades del maestre de Campo de la ciudad de Manila, don Esteban de Eguiño, se incluyen «doce tablas de maque negro para biobo de estrado» que pudieron ser montadas por algún artesano especializado o reutilizadas en la elaboración de otro tipo de muebles como en ocasiones sucedía en Europa. ${ }^{16}$

Los talleres chinos, dada la creciente demanda occidental de muebles de lujo que se venía desarrollando desde la segunda mitad del siglo XVI, comenzaron a elaborar biombos expresamente para la exportación. Coetáneamente al inicio de la producción en Cantón de porcelana para los mercados europeos, se realizaron un tipo de «biombos de encargo» con temas occidentales sacados de pinturas o grabados europeos que eran interpretados a la manera oriental. Se trataba de asuntos y composiciones nuevos para los artesanos asiáticos, pero que se adaptaban al gusto de sus clientes tanto europeos como americanos. Por lo tanto, estos biombos se integran dentro de un fenómeno más amplio de desarrollo de una producción artesanal china destinada a cubrir las exigencias de la élite de estos dos continentes.

Desde finales del XVII se produjo un incremento de la exportación de los biombos chinos llamados erróneamente de Coromandel. Esta denominación deriva de la costa de la India del mismo nombre, sobre el golfo de Bengala, desde donde eran embarcados a Europa, pero la mayoría procedía de las provincias chinas de Fujian, Zhejiang, Jiangsu y Anhui. ${ }^{17}$ Esta confusión explica que la mayoría de los biombos que encontramos en Portugal y muchos de los que aparecen en España sean registrados en las fuentes como «de la India». ${ }^{18}$ Es de suponer que, al ser un importante centro redistribuidor de biombos del norte de China, alguno pudo ser embarcado con destino a Manila, desde donde su paso a Acapulco resultaría muy atractivo. No obstante, a tenor de las fuentes es más probable suponer que los biombos que salían de las costas del golfo de Bengala se destinasen fundamentalmente a Europa, mientras que, para el caso de Filipinas y América, este tipo de muebles chinos llegaría directamente desde Cantón o Macao,

15 AGI, Filipinas, $942,5,145 \mathrm{v}$ y $187 \mathrm{v}$.

16 AGI, Filipinas, $170,4,14 \mathrm{v}$.

17 Castelló y Martínez, 1970, 12.

18 En el caso de los biombos transportados por holandeses podían denominarse como «de Bantam», en referencia al puerto de Java desde el que se exportaban a Europa. 
mucho más próximos. Este hecho explicaría que los biombos registrados en Manila nunca sean calificados como «de la India» 0 «de Bantam», sino que siempre se hace alusión a su factura china o japonesa.

En cuanto a los biombos producidos en Japón, éstos podían alcanzar Manila a través de los japoneses que se trasladaban a Filipinas para negociar directamente o por medio de los europeos que tenían tratos en Nagasaki. A inicios del siglo XVII, algunos españoles se dirigían hasta Japón para comprar muebles, como sucedió con los que se vendieron en 1613 al inglés John Saris. ${ }^{19}$ Sin embargo, los que más abundaron en este tráfico hasta mediados del siglo XVII fueron los japoneses y portugueses. Así lo recogió Antonio de Morga, quien no pudo pasar por alto en su crónica sobre las Filipinas la importancia de estos comerciantes, señalando a los biombos entre las mercancías habituales que se enviaban a Nueva España:

De Japón, vienen asimismo cada año del puerto de Nangasaque, con los Nortes de fin de octubre, y por el mes de marzo, algunos navios de mercaderes, japones y portugueses, que entran y surgen en Manila, por la misma orden; la gruesa que traen es harina de trigo, muy buena para el abasto de Manila, cecinas estimadas; algunas sedas tejidas de matices, curiosas, biouos al olio y dorados, finos y bien guarnecidos; [...]. En esto, se hacen también algunos empleos, sin que se cobren derechos reales destos navios, y lo mas se gasta en la tierra, y dello sirve para cargazones a la Nueva España. ${ }^{20}$

Entre 1590 y 1635 anclaron en Manila 58 embarcaciones japonesas cargadas de productos y se calcula que hubo una población permanente de 500 personas de esta nacionalidad, la mayoría comerciantes y cristianos. ${ }^{21}$ La relación no se vio interrumpida por los enfrentamientos religiosos o el aislamiento del país. Sin embargo, después de 1635 la población japonesa se reduce y se aprecia una entrada mucho menor de sus barcos, siendo que desde esta fecha hasta el año 1700 se registraron tan sólo 13, evidencia de las dificultades impuestas por la nueva coyuntura política. ${ }^{22} \mathrm{~A}$ partir de mediados del siglo XVII los holandeses sustituyeron a los portugueses como distribuidores de objetos japoneses. No obstante, la VOC, al margen del contrabando, necesitó de intermediarios autorizados para tratar en Cavite si deseaba introducir sus mercancías en el circuito español.

19 Satow, 1967.

20 Morga, 2007, 289-290.

21 Chaunu, 1976, 142-169. Morga, 2007, 299. En los registros de la Hacienda de Filipinas de finales de la década de 1630 se pueden observar los pagos que hicieron numerosos japoneses para obtener una licencia con la que se les permitiese residir en Manila. AGI, Contaduría, 1217, 77v-78r.

22 Chaunu, 1976, 142-169. 
Si queremos rastrear la presencia de biombos japoneses entre las propiedades de los personajes más ricos de Filipinas o Nueva España, nos encontramos con el problema de la falta de interés de los productores de las fuentes conservadas por especificar el origen de los objetos o de hacerlo con rigor geográfico. En muchos de los inventarios de bienes analizados sólo aparece el tamaño y el precio de los biombos, sin más explicación, o se califica libremente a todos los llegados a través del galeón de Manila con el adjetivo genérico de «chinos», lo que impide distinguir los diferentes lugares de fabricación. No obstante, también se encuentran casos donde se especifica su procedencia japonesa, lo que probaría la larga relación comercial entre Nueva España y Japón. En los inventarios de bienes de la ciudad de México aparecen consignados varios de estos muebles. En 1626, el mercader Pedro de Burgos cuenta con un biombo de Japón «pintado y dorado» que se califica como viejo, lo que indicaría la existencia temprana en el virreinato de este tipo de muebles; a mediados del siglo XVII, Ana María Gomes de la Madriz o la viuda del capitán Tomas Aguirre Hirsnaba tenían cada una un biombo japonés de ocho hojas; ${ }^{23}$ mientras que en 1733 , entre las propiedades de Josefa del Castillo, mujer del capitán José Fernández de Córdoba, se enlista un biombo japonés entre varios de factura novohispana. ${ }^{24}$ Pero quizás el testimonio más evidente de que el vínculo entre Manila y Japón se mantuvo después de que el país se cerrara para los católicos lo hallamos en el registro de propiedades del antiguo gobernador de Filipinas, don Fausto Crusat y Góngora, que en 1706 contaba con once biombos nipones entre sus propiedades. ${ }^{25}$

En el caso de Perú, merced a la exclusividad de la que gozaba Acapulco en el trato con Filipinas, la mayoría de las mercancías asiáticas que arribaron al Callao lo hicieron a través del comercio irregular con Nueva España. Después de algunos contactos directos a finales del siglo XVI, tendremos que esperar hasta el siglo XVIII para volver a encontrar cargamentos venidos directamente desde Asia. En las dos primeras décadas de este siglo, los trastornos ocasionados por la guerra de sucesión espa-

23 Archivo General de la Nación de la ciudad de México (AGN), Civil, 1835, 6 y AGN, Civil, 1863, 19 y también Archivo Histórico de Notarías de la ciudad de México (AHNMéx.), Toribio Cobian, esc. 110, 726, 1655.

24 AGN, Civil, 1327, exp. 1, 18r. Además, Gustavo Curiel, en la lista que publicó sobre biombos consignados en documentos notariales de la ciudad de México, cita dos biombos japoneses más: en 1679 un «biobo grande del Japón, todo dorado» y en 1683 otro biombo japonés de ocho hojas con «flores y animales», Curiel, 1999, 9-32.

25 AGN, Civil, 114, exp. 1. 
ñola provocaron que las flotas de galeones fueran sustituidas por barcos franceses sueltos, quienes aprovecharon la coyuntura para encaminarse directamente a Cantón e inundar el Callao con mercancías chinas. Además, la Compañía de Filipinas gozó de una oficina permanente en Lima y varios de sus barcos llegaron a sus costas cargados con productos de Asia. Es probable que, como sucedía con los buques españoles y portugueses que navegaban en el Pacífico, en sus bodegas se incluyese algún mueble de lujo. Por lo tanto, alguno de los biombos chinos que hemos documentado en Lima para el siglo XVIII también pudo haber utilizado esta vía de acceso.

\title{
El comercio de biombos entre Filipinas y Nueva España
}

Manila supuso la puerta por la que el conjunto de mercancías asiáticas entraban cada año en Nueva España a cambio de la tan codiciada plata americana. El éxito de los biombos como producto suntuoso inserto en el comercio transpacífico entre los puertos de Cavite y Acapulco resulta indiscutible. La referencia de Rodrigo de Vivero y Velasco a los biombos que ya habían llegado al virreinato antes de su retorno a principios del siglo XVII demuestra una vez más la pronta propagación de estos objetos y el interés por establecer una importación estable de los mismos:

\begin{abstract}
Hase trato diversamente qué efectos buenos al servicio de Dios y del rey nuestro señor podía surtir abrirse trato desde Japón a la Nueva España, porque pinturas, biombos, escritorios, y lo que otra vez se trajo, no es mercadería para ordinario, pero esta misma razón me hace mayor fuerza para tener por buena la contratación, porque si la Nueva España cambia lo inútil y lo superfluo, como son paños, añil, granos, cueros, fieltros, sombreros, vino... y por eso se le retorne plata, oro, que tanto abunda y tanto es menester acá, no hace fuerza la razón contraria que se funda en que los géneros del Japón no sean necesarios en la Nueva España. ${ }^{26}$
\end{abstract}

En los casos en los que contamos con la lista de mercancías transportadas en la nao de China, comprobamos la existencia constante de biombos. Gaspar Álvarez, secretario de gobernación y guerra de las Islas Filipinas, envió a Acapulco en 1611 y en 1617 varios cajones de biombos. ${ }^{27}$ En 1680, el capitán don Luis Morales registró en el galeón Capitana Santelmo «dos biobos grandes divididos en seis cajoncillos, de a cuatro

26 De Vivero, 2003, 27.

27 AGI, Contratación, 368, 7, 1, 64v y 65v. 
tablas cada uno», ${ }^{28}$ mientras que en 1684 el capitán Francisco Antonio de Velasco o Tomas Enríquez incluyeron varios cajones de biombos entre los bienes que remitieron al virreinato. ${ }^{29}$ Ya en el siglo XVIII, el sargento mayor, don Domingo Antonio de Otero Bermudes, apuntó en el libro de sobordo del galeón Santo Cristo de Burgos que en 1716 realizó el trayecto hasta Nueva España dos cajones de biombos «regulados por cuatro piezas»..$^{30}$ Asimismo, en 1771 el Consulado de Manila realizó un informe en el que se recogían las mercancías que se despacharon en los galeones que fueron a Nueva España entre 1736 y 1740, apareciendo consignados en las listas varios biombos y rodaestrados de doce tablas, con la evolución de sus precios. ${ }^{31}$ En este mismo documento se registraron para el año de 1770 rodaestrados de veinticuatro hojas maqueados y un «beobo de maque colorado con flores doradas de dos caras de 24 hojas». ${ }^{32}$ A estos datos oficiales debemos sumar todos aquellos biombos que llegaron de forma ilegal y que, por lo tanto, son también muy difíciles de consignar en las fuentes. ${ }^{33}$

Asimismo, los intentos por regular el tráfico de estas piezas son la mejor prueba de su presencia habitual. En la real cédula de 1726 dirigida al marqués de Torrecampo, gobernador de Filipinas, en la que se le informa sobre la reglamentación del comercio de las islas con Nueva España, se hace alusión a los biombos, a cómo debían embarcarse y a la tasa que tenían que pagar. De donde se deduce que esta mercancía ocupó un papel lo suficientemente significativo dentro del conjunto de las exportaciones como para que se reparara en la misma. ${ }^{34}$

Una vez llegaban los cargamentos a Acapulco, estos se distribuían entre comerciantes mexicanos y de otras partes de América en la feria que se celebraba en esta misma ciudad. Dadas las conexiones que tenían los novohispanos en Manila, la mayoría de los productos continuaban el viaje hacia la ciudad de México. ${ }^{35}$ La importancia de este trato quedó evidenciada por el hecho de que la ruta que unía el puerto del Pacífico y la capital se

28 AGI, Escribanía, 411A, 286v.

29 AGI, Escribanía, 411A, 393r y 398r.

30 AGN, Marina, 1, 11, 114r.

31 AGI, Filipinas, 967, 47r, 47v, 55v, 66r, 72v, 81r.

32 Ibidem, 121v.

33 En los barcos que arribaron a Acapulco en 1612 se requisaron «dos pares de biovos», AGI, Contaduría, 902.

34 «Normas para el comercio entre Filipinas y Nueva España», AGI, Filipinas, 342, 9, $223 r-228 r$

35 Sobre la influencia de los comerciantes mexicanos en Filipinas ver: Yuste, 2007. 
denominó «camino de la China». Además, la Real Aduana también nos ha dejado algunas evidencias de la entrada de biombos asiáticos. Entre los géneros de China introducidos en la ciudad por el navío San José de Gracia en 1784 y 1787 , se registraron varios «biombos maqueados en tabla y con figuras doradas» a 96 pesos la pieza. ${ }^{36}$

Desde inicios del siglo XVIII, en la Plaza Mayor de la ciudad de México se situó el Parián, conocido así por ser el lugar donde se vendían los productos que llegaban desde Filipinas. Entre estas mercancías se podían hallar muebles de lujo, muy demandados por los ricos criollos para adornar sus palacios. Juan de Viera nos narra como «en ese mercado hay camas, biombos y estrados... en fin se puede poner una casa dentro de una hora para recibir potentados». ${ }^{37}$ En varias pinturas del siglo XVIII en las que aparece representado el Parián podemos comprobar que los biombos estuvieron entre los objetos puestos a la venta, como sucede en el cuadro de la Plaza Mayor conservado en el Museo Nacional de Historia de la ciudad de México, fechado para 1766, o en el perteneciente a la Fundación Banamex.

El análisis de los inventarios de bienes, testamentos y dotes de las familias más prósperas del virreinato durante los siglos XVII y XVIII revela la popularidad de los biombos asiáticos entre el mobiliario de los principales palacios de la capital mexicana. A la fascinación occidental por todos aquellos objetos lejanos, rodeados de un halo de «exotismo», se unía en Nueva España la dificultad de acceder a los productos europeos y el lugar privilegiado que, por el contrario, ocupaba en el comercio internacional con Asia. Los tapices, que en los palacios del viejo continente rodeaban las paredes de los cuartos principales, eran escasos y muy caros en América, por lo que habitualmente fueron sustituidos por biombos que recubrían los muros del salón de estrado, mucho más accesibles.

Los propietarios novohispanos de estos objetos formaban parte de un grupo de «nuevos ricos» surgidos de la conquista, poblamiento y explotación de América que, ante la falta de títulos nobiliarios o linajes que respaldasen su ascenso social, buscaron símbolos de estatus que expresaran la posición recientemente adquirida. En este sentido, los biombos llegaron en el momento preciso al sitio adecuado y toda familia rica que se preciase

36 AGN, Indiferente Virreinal, caja-exp. 6450-090 y caja-exp. 6450-091 (Agradezco a la arqueóloga Andreia Martins Torres que me facilitara esta referencia).

37 Viera, 1952, 41. 


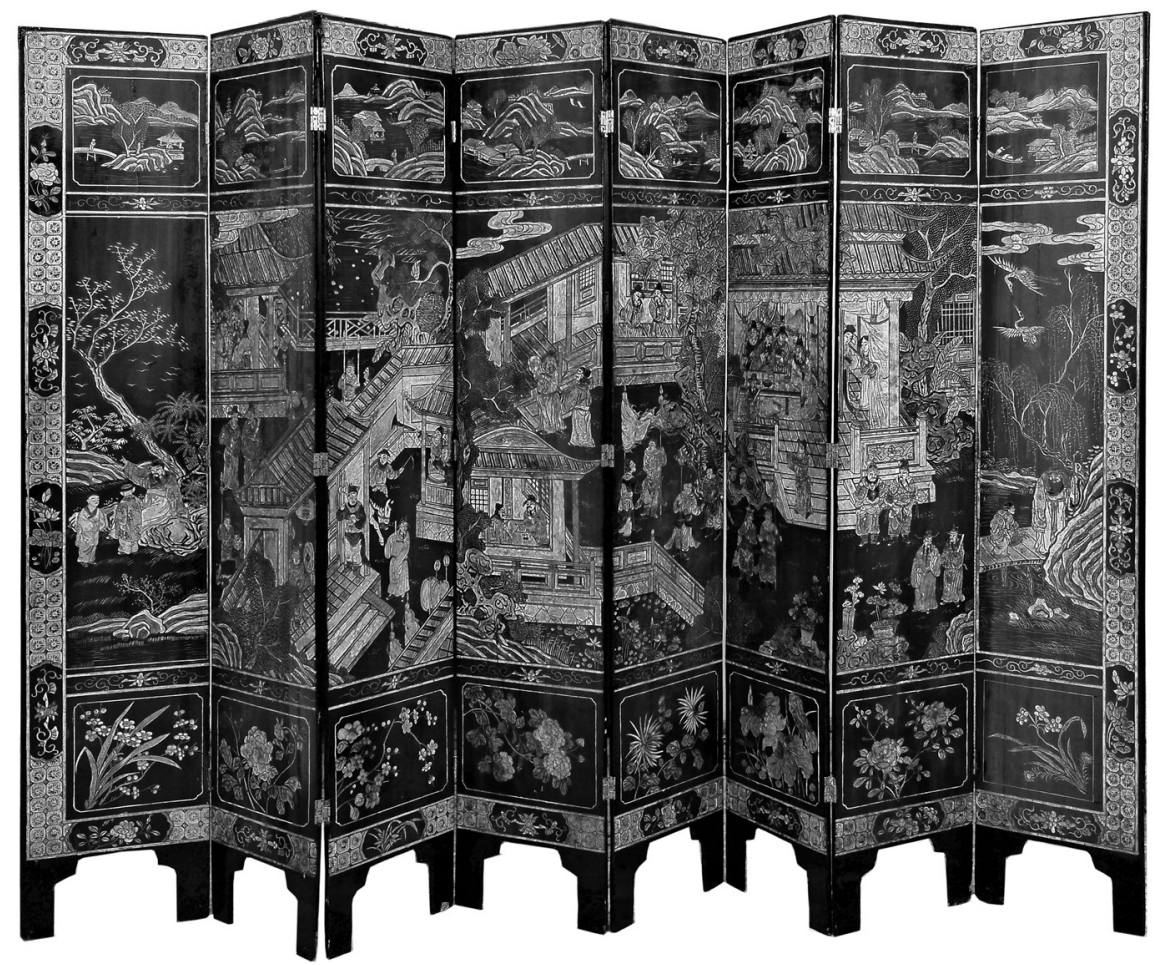

Biombo chino de exportación, Museo Amparo, ciudad de Puebla, México.

contaba con varios de estos muebles. La marquesa doña Teresa Francisca María de Guadalupe Retes, por ejemplo, tuvo ocho biombos repartidos por sus casas, uno seguro de origen chino ${ }^{38}$ mientras que entre los objetos de valor del Conde de Xala se listan un biombo de maque de China de 240 pesos y «otro dicho de China con once hojas». ${ }^{39}$

Es interesante consignar que durante el siglo XVII, paralelamente al comercio con Filipinas, se desarrolla en Nueva España una manufactura de biombos propia que adquiere un volumen muy importante, hasta competir en el mercado de exportaciones con los de manufactura asiática. El nacimiento de esta producción en el virreinato, al margen de la influencia que

38 Curiel, 2000, 65-101.

39 Romero de Terreros, 1957, 60. 
eventualmente pudiera tener la llegada de algún artista foráneo, se debió a una serie de factores internos y a las consecuencias derivadas del papel central que ocupaba Nueva España en el tráfico internacional. Dejando a un lado las consideraciones artísticas, hay que subrayar la oportunidad económica que la demanda de este mueble abría para los artesanos locales. Al eliminar el gasto derivado del transporte y los intermediarios, los biombos «achinados» ofrecían precios mucho más baratos que los chinos o japoneses, normalmente entre los 5 y los 16 pesos, y sólo en algunos casos hechos «al remedo de maque» o de «maqué fingido» fueron valorados entre los 30 y los 50 pesos, muy lejos de los 100 pesos que costaba de media un biombo asiático nuevo. Lo mismo sucedía con los ejemplares mexicanos pintados con temas occidentales, que contaban con un valor un poco más alto que los «achinados» pero aún muy lejos del precio de los que llegaban en el galeón de Manila. El éxito progresivo de esta producción hizo que durante el siglo XVIII se extendiera tanto su uso que resulta muy difícil no encontrar varios biombos entre las propiedades de cualquier español con cierta fortuna, si bien los chinos fueron más exclusivos $\mathrm{y}$, por lo tanto, menos frecuentes.

Durante esta centuria, además de la producción novohispana, vemos surgir manufacturas en otras partes de América como Perú, Guatemala o Colombia que se adaptaron perfectamente al gusto local y a los materiales utilizados comúnmente en los muebles de la tierra. ${ }^{40}$ Expresión artística de una nueva identidad criolla, no podemos detenernos en este asunto, pero conviene apuntar que en el futuro el estudio de los temas representados en sus hojas podrá arrojar luz sobre la posible influencia que las obras novohispanas tuvieron en el resto de América.

\section{El viaje por el Atlántico y por el Pacífico Sur}

Una parte de las mercancías que llegaban con el Galeón de Manila hasta la ciudad de México se reenviaban hacia Veracruz para ser embarcadas con dirección a España. Desde finales del siglo XVI y principios del

40 En Perú encontramos biombos hechos en «pintura del reino» o en «pintura de Lima», además de otros ejemplares en vaqueta dorada de Huamanga. AGL, Protocolos notariales, 76, esc. Orencio de Ascarrunz, 1750, f.553r; AGL, Protocolos notariales, 871, esc. Agustín Gerónimo de Portalanza, 1761, 338v. En Colombia se conservan dos biombos con temas costumbristas hechos en la tierra: López Pérez, 1998. 
XVII, Europa se vio inundada por una avalancha de productos asiáticos de carácter suntuario y de uso cotidiano, destinados en la mayoría de los casos a regalos o a colecciones particulares. Los puertos de entrada de estas mercancías fueron Lisboa y Sevilla, donde pronto se extendió entre las principales familias enriquecidas por el comercio el gusto por los objetos venidos de lugares lejanos. ${ }^{41}$ El estudio de los libros notariales del Archivo de Protocolos de Sevilla refleja el auge que tuvieron los biombos entre los enseres domésticos de los comerciantes y funcionarios de la ciudad, especialmente entre aquellos relacionados con la carrera de Indias durante los siglos XVII y XVIII. ${ }^{42}$

Si bien coincidimos con María Jesús Sanz y María Teresa Dabrio en destacar cómo entre aquellos individuos implicados en el tráfico con América se encontraban riquísimos ajuares, superiores muchas veces a los de los nobles de la ciudad, discrepamos respecto a su opinión de atribuir a este grupo una preferencia por los objetos importados de Asia frente al supuesto gusto más tradicional de los aristócratas. ${ }^{43}$ Una lectura atenta de los inventarios de bienes de Sevilla demuestra que el interés por estas obras no fue exclusivo de los comerciantes y funcionarios sino que, por el contrario, también se extendió entre las familias nobles. ${ }^{44}$

Asimismo, desde el inicio de las relaciones ibéricas con Asia, la realeza española y la portuguesa tuvieron un gran interés por acceder a las mejores piezas que ofrecían aquellas culturas lejanas. Muchas fueron

41 Juan Gil ha publicado un estudio en el que presenta una relación de los productos de Extremo Oriente que llegaron hasta Sevilla durante el siglo XVII en base a la documentación del Archivo de Indias de Sevilla. Gil, 2011.

42 Los biombos fueron habituales entre las propiedades de los miembros del Consejo de Indias, de la Casa de Contratación o del Consulado de Sevilla: Domingo de Urbizu, miembro del Consejo Real de Hacienda y alguacil mayor de la Casa de Contratación, presenta varios biombos en su ajuar doméstico; Ignacia Calzado, mujer de Esteban Torrado de Guzmán, contador y secretario del Consulado de Sevilla, «un biombo grande de liensso pintado» (ambos citados por Sanz y Dabrio, 1974, LVII, 89-150); además encontramos otro ejemplar propiedad de Juan de Torres y la Vega Ponce de León, conde de Miraflores de los Ángeles y presidente de la Casa de Contratación, que en la almoneda celebrada por su muerte sería vendido a Manuel de Torres, miembro de la Real Audiencia de la ciudad de Sevilla, por 120 reales de vellón. Archivo Histórico Provincial de la Ciudad de Sevilla (AHPS), $1,1,1721,498 \mathrm{r}$.

43 Sanz y Dabrio, 1974, 89-150.

44 Así, Simón de Gaviola, caballero de la orden de Santiago, y su mujer tuvieron cuatro biombos (AHPS, 14, 1, 1653, 1203r y 1214v.); don Francisco Tello y Portugal, marqués de Sauseda y caballero de la orden de Alcántara, tuvo «dos biombos de China» en su poder (AHPS, 13, 2, 1702, 1623 1634); doña Ana María Fernández Altamirano, propietaria de una hacienda de olivares cerca de la ciudad, «un biombo de ocho hojas pintado» (AHPS, 1, 1, 1721, 325v.); o doña Ana Tello de Guzmán, viuda de don Lorenzo Dávila y Medina, conde de Valhesmoro, «un biombo de lienzo pintado» (AHPS, $1,1,1727,445 \mathrm{r})$. 
adquiridas como regalos llevados por las embajadas o enviadas por los funcionarios reales desplazados a aquellas regiones que buscaban ganar el favor en la Corte, mientras que otras fueron simplemente compradas por encargo. La unión de las Coronas ibéricas propició que, durante sesenta años, las dos rutas que ligaban Europa con Asia quedaran bajo un mismo monarca, lo que facilitó aún más el tráfico de objetos «exóticos» hacia la Corte de los Felipes. Después de la ruptura hispano-lusa de 1640, los reyes españoles siguieron demandando este tipo de muebles para la decoración de sus palacios, como puede apreciarse por su popularidad dentro de las colecciones reales de los siglos XVII y XVIII. Así, Carlos II, en el inventario de pinturas del Palacio Real de Madrid, tenía un biombo de nueve hojas de charol «de la india», seguramente denominado así por haber sido importado desde la costa de Coromandel. ${ }^{45}$ Entre los bienes de Isabel de Farnesio de 1745 se mencionan «dos biombos de charol y nácar con pintura fina» heredados de su tía Mariana de Neoburgo, la última esposa de Carlos II. ${ }^{46}$ Carlos III, por su parte, contó con numerosos biombos repartidos entre sus diferentes palacios, algunos para su uso personal y otros para las infantas. ${ }^{47}$

Al margen de los biombos chinos y japoneses que alcanzaron la Península, muchos de los producidos en Nueva España también partieron rumbo a Europa durante los siglos XVII y XVIII. De esta forma, es posible encontrar estos muebles mexicanos incluidos en el ajuar doméstico de las familias nobles tanto de Sevilla como de Madrid. En el inventario de 1683 del palacio sevillano de doña Inés María de Molina y Bermúdez se lista un impresionante biombo de estrado de las Indias de veintiséis paneles de lienzo pintado. ${ }^{48}$ En Madrid, por su parte, en el inventario de 1646 de

45 Fernández Baytón, 1975, 118 y 124.

46 Arte y Saber, 1999, Inv. 207.

47 Entre las pinturas del Palacio Real de Madrid, Carlos III contaba con un «un biombo de charol negro con varias pinturas de aves y árboles de doce hojas»; en el real Sitio de San Lorenzo había cinco biombos de tela, hechos en damasco carmesí, filipichín encarnado y bayeta encarnada; en San Ildefonso un biombo de damasco amarillo; en el real sitio del Pardo, en el cuarto del rey se encontraban «dos biombos de ocho hojas cubiertos de damasco carmesí con galón de oro y tachuela dorada», mientras que en el de las infantas niñas había «uno de ocho hojas de doblar de caoba, cubierto su bastidor de damasco carmesí, trenzas y borlas correspondientes, que sirve a SS. AA delante de las chimeneas» Fernández Miranda, 1988, 1, 220 y 448 y 2, 353, 371 y 421.

48 AHPS, 14, 2, 1683, 229-235. Además, la localización más antigua que se conoce del biombo del palo del volador del Museo de América de Madrid es el Hospital de la Caridad de Sevilla, en cuya hermandad ingresaban los personajes mas importantes de la ciudad, alguno de los cuales debió donar la obra. Sandoval, 2007. 
Álvaro de Bazán, marqués de Santa Cruz, se incluían «dos biombos traídos de las Indias» tasados en 600 reales, ${ }^{49}$ mientras que entre los bienes inventariados en 1653 al conde de Monterrey se citan «cuatro biombos de las Indias.$^{50}$ Por último, en la testamentaría de Isabel de Farnesio también aparece un biombo que representaba la conquista de México, de veinticuatro paneles con pintura y madre perla, prueba de que estos objetos fueron valorados tanto como sus homólogos orientales. ${ }^{51}$

También desde la costa occidental de Nueva España, a pesar de las restricciones del siglo XVI y a la prohibición posterior del tráfico entre virreinatos, partieron rumbo al Callao muchos productos llegados en el Galeón de Manila. Los comerciantes peruanos idearon distintas formas de acceder a estas mercancías, como el trasbordo en puertos intermedios o el contrabando a bordo de navíos que transportaban azogue. ${ }^{52}$ Como señala Bonialian, un número importante de barcos peruanos navegaban cada año hasta los puertos de Acapulco, Zihuatanejo, Huatulco, Realejo y Sonsonate, transportando plata, azogue, cacao y vino, y retornaban tiempo después cargados con mercancías europeas, mexicanas y asiáticas. ${ }^{53}$ Entre estos objetos se encontraron los biombos, tanto los de origen chino como los de factura mexicana. Como sucede con el resto de territorios analizados, nuevamente encontramos a ricos comerciantes y funcionarios entre los dueños de estos objetos. La existencia de varios ejemplares asiáticos en Lima durante el siglo XVIII demuestra cómo el virreinato peruano estuvo conectado con el comercio de Extremo Oriente, bien fuese directamente o, más probablemente, a través de su relación con Nueva España. ${ }^{54}$ Además, la presencia de biombos mexicanos en Sudamérica nos indica que la producción en este territorio tuvo un volumen notable, que fueron valorados

49 AHPM, 5892, 841r, 11 de agosto de 1646.

50 Hay otros seis biombos en este inventario, dos de ellos también de las Indias, AHPM, 7684, $1653,283-284$.

51 Arte y Saber, 1999, Inv. 207.

52 Calderón, 2003, 586

53 Bonialian, 2011, 15-16

54 Fueron propietarios de biombos chinos en Lima durante el siglo XVIII los siguientes personajes: el sargento mayor Gaspar Fernández de Montejo (Archivo General de la Nación en Lima, AGL, Protocolos notariales, 1, esc. J. Agüero, 1732, 629v.), Isabel Carrillo de la Presa, dueña de un molino de pólvora y del navío La Soledad (AGL, Protocolos notariales, 83, esc. O. Ascarrunz, 1765, f. 302r.), Juana Ignacia de Gomendio, poseedora de un cajón de textiles (AGL, Protocolos notariales, 2, esc. Joseph de Agüero, 1734/35, 921r.), el Maestre de Campo Francisco de Oyague (Archivo Riva Agüero, ARA, Sección colonial, C-58, 38r), o el miembro del Consejo de Indias y oidor decano de la Real Audiencia de Perú, Álvaro de Navia Bolaño, conde del valle de Oselle (AGL, Protocolos notariales, 509, González Mendoza, 1757/1760, 468r y 651r). 
más allá de sus fronteras y que alcanzaron no sólo Europa, como se pensaba hasta ahora, sino también el resto del continente americano. ${ }^{55}$

\section{El movimiento de personas y los biombos}

\section{Embajadas}

La llegada de los primeros biombos a Nueva España y Europa fue paralela a los contactos diplomáticos entre los reinos ibéricos y Japón, y a la consolidación del comercio en el Pacífico, tanto en su vertiente occidental como a través del Galeón de Manila. Los primeros ejemplares de los que tenemos noticia no arribaron a Europa de la mano de los comerciantes sino de la iniciativa de los religiosos. Fueron los japoneses que componían la embajada que partió de Nagasaki junto al jesuita Alejandro Valignano rumbo a Lisboa en 1582, quienes dieron a conocer estos muebles. Entre los presentes embarcados por la embajada se encontraban dos pares de biombos, los dos primeros ofrecidos a Felipe II y los otros dos al papa Gregorio XIII.

A principios del siglo XVII, tan sólo algunos años después de que esta misión visitase la Corte de Felipe II y el Vaticano, entre la relación de objetos que el embajador de Japón traía con el fin de venderlos para su despacho en Madrid, se hace mención de «Treynta Caxones de biobos de oro fino, cada Caxon dos biobos». ${ }^{56}$ Prueba de que, nuevamente, los propios japoneses colaboraron en la difusión por Europa de un mueble de lujo que se consideraba típicamente oriental, pero que poco a poco iba ganando un espacio en los salones de los principales palacios de occidente.

En América, la primera noticia que tenemos sobre una presencia oficial de japoneses data de 1610. Rodrigo de Vivero, después de su mandato como gobernador de Filipinas, naufragó en Japón durante su regreso a México y el shogun Ieyasu le ofreció un buque construido en sus astilleros para que continuase su viaje de retorno. Junto a Rodrigo de Vivero embarcaron una embajada de 23 japoneses encabezados por Tanaka Shosuke con

55 Además, encontramos biombos mexicanos entre las propiedades de: Diego de Carbajal, corredor mayor del reino (AGL, Protocolos notariales, 64 esc. Arredondo 1731, 260v-266v y 291r-297r), Fernando Carrillo, sargento del batallón de milicias de la ciudad de Lima, (AGL, Protocolos notariales, 67, esc. Antonio José de Ascarrunz, 1748) o Josefa Jiménez Lobatón y Salazar, madre de don José de Rezabal y Ugarte, regente de la Real Audiencia de Santiago de Chile (AGL, Protocolos notariales, 144, esc. Lucas de Bonilla, 1794, 91r-120v).

56 «emoria de mercaderías que trae el embajador de Japón», AGI, Filipinas, 7, 7, 88. 
el cometido de aprender la técnica del beneficiado de la plata y de consolidar una relación comercial directa entre ambos reinos. Además, ese mismo año, el gobernador de Filipinas, Juan de Silva, informó al rey que había recibido del citado shogun varios biombos de poca calidad como gesto de amistad. ${ }^{57}$

En 1611, Tanaka emprendió el camino de vuelta a Japón uniéndose a la expedición de Sebastián Vizcaíno, primer embajador enviado al país nipón por Felipe III con el propósito de impulsar los lazos económicos y políticos. En estas misiones diplomáticas eran obligatorios los regalos y en este apartado tuvieron un protagonismo especial los biombos, lo que vino a establecer desde el primer momento su papel como objetos distinguidos. Iyesasu respondió a los presentes de la misión española enviando al virrey Velasco el Joven diez biombos tejidos de oro, tres armaduras de samurai y una carta geográfica del Japón, obsequios que recibió en 1614 su sucesor en el cargo, el marqués de Guadalcázar, quien finalmente los haría llegar a don Luis de Velasco..$^{58}$

Adquiridos por los virreyes, los biombos pronto ocuparon un lugar principal entre los muebles de las casas reales de Chapultepec. En 1640, por ejemplo, se dispusieron dos ejemplares chinos «que cubrían la música e instrumentos» mientras se servía el banquete de recepción al virrey Diego López Pacheco. ${ }^{59} \mathrm{La}$ vida en la corte virreinal constituía en México el modelo aristocrático que trataban de imitar las principales familias novohispanas, por lo tanto, el hecho de que llegaran biombos entre las ofrendas de las comitivas japonesas o su uso en los palacios oficiales, hizo que se extendiera la imagen de este mueble como elemento de prestigio y que muchas de las familias más ricas de la ciudad quisieran hacerse con uno para lucir en sus salones. Asimismo, en la cultura política de la época se incorporó la imagen del biombo como mueble especialmente apropiado para regalar si se quería obtener algún favor o simplemente agradar al destinatario. Ejemplo de ello son los biombos que enviaron los virreyes novohispanos a la península o el «arrimador de estrado» que en 1663 ofreció el gobernador de Nuevo México, Diego de Peñalosa, al contador de la ciudad de México, Carlos de Sigüenza. ${ }^{60}$

57 «Carta de D. Juan de Silva al rey», AGI, Filipinas, 20, 4, 36, 15 y 16.

58 Castelló y Martínez, 1970, 27.

59 Gutiérrez, 1947, 74.

60 AGN, Tierras, 3283, 2, 54-61. Los biombos también fueron denominados arrimadores de estrado en Nueva España. 


\section{Funcionarios reales, comerciantes y mercaderes}

La conformación de la Monarquía Católica durante el siglo XVI produjo un conglomerado de relaciones planetarias que conllevaría la constitución de burocracias móviles y un sistema económico de dimensiones mundiales. Serge Gruzinski ha llamado la atención sobre una «elite mundializada» que se movió a través de las fronteras de los dominios españoles y portugueses, ambos íntimamente relacionados. ${ }^{61}$ Este grupo de individuos propició de manera inconsciente una nueva cultura que superó los límites imperiales y que se vio influida por todas aquellas civilizaciones con las que entró en contacto. A lo largo de la Edad Moderna, el transporte de biombos acompañó al movimiento de personas, en especial al de mercaderes y cargos reales desplegados por cuatro continentes, sirviendo como testimonio de los cambios producidos.

Virreyes y gobernadores fueron unos grandes consumidores de obras de arte, bien fuese para incorporar a su propio ajuar o para enviar a la Península. Así, después de su mandato en Nueva España, muchos transportaron hasta su nuevo destino los biombos que habían adquirido. Los temas representados en las hojas de estos muebles podían ser varios: los lugares más emblemáticos de la capital, como la Alameda, el paseo de Iztacalco o la Plaza Mayor; hechos históricos relevantes como la conquista de México, que solían acompañarse por una vista aérea de la urbe por su otra cara; representaciones de algunas de las prácticas más pintorescas de la tierra, como los desposorios indígenas y los ritos prehispánicos asociados al festejo de los mismos; o historias mitológicas apropiadas para espacios privados. ${ }^{62}$ Estos biombos pudieron servir a sus dueños de recuerdo de su paso por aquella ciudad, de los méritos adquiridos en el embellecimiento de la urbe, o simplemente como símbolo de cosmopolitismo ante sus invitados peninsulares. Muchos de los temas elegidos encajaban perfectamente con el gusto aristocrático de la época, que buscaba saciar la curiosidad por conocer «otros mundos» a través de la representación en sus salones de escenas costumbristas. De cualquier manera, los biombos no constituyeron un caso especial y deben ser relacionados con los enconchados, trabajo típicamente novohispano del que se han documentado envíos a la Península

61 Gruzinski, 2010.

62 Baena, 2007, 441-450. 
con el tema de la conquista, ${ }^{63}$ o con los cuadros pintados con vistas de la plaza de la ciudad de México que fueron encargados por funcionarios $\mathrm{u}$ ofrecidos por la ciudad al final de su estancia. ${ }^{64}$

El primer ejemplo que encontramos de funcionarios que se trasladaron desde México cargando con un biombo producido en la tierra es el que aparece consignado en Madrid en el inventario de bienes de 1617 del virrey Luis de Velasco el Joven o hijo. Puesto que se indica que el biombo era «de las Indias», lo lógico es pensar que lo adquirió en México antes de su partida en 1612, fecha que nos sugiere cómo para inicios del siglo XVII ya estaba activa la producción de biombos en Nueva España. ${ }^{65}$

El biombo, que representa la «Vista de la Plaza Mayor de la ciudad de México y del paseo de Iztacalco», descubierto en España y actualmente en la colección Rivero Lake, muestra en su parte superior el escudo del marqués de Cadereita, virrey de la Nueva España entre 1635 y 1640. Puede que el interés de este gobernante fuera mostrar la ciudad en todo su esplendor, dado que emprendió numerosas obras para mejorar su drenaje y para reparar los daños producidos por un terremoto. Incluso, parece que en la Plaza Mayor pudo representarse a sí mismo saliendo con su comitiva de Palacio en un ambiente festivo.

El biombo, en el que aparecen por un lado «Las artes liberales» y por el otro «Los cuatro elementos», fue pintado por Juan Correa siguiendo las indicaciones del virrey fray Payo Enríquez de Ribera, arzobispo y virrey entre 1667 y 1679 . Una vez se hubo cumplido su periodo de gobierno en las Indias, fray Payo trasladaría esta pieza entre su ajuar hasta la Península, donde permanecería hasta su incorporación a la colección del Museo Franz Mayer. ${ }^{66}$ Otro virrey que aprovechó su breve estancia en la ciudad de México para hacerse con alguno de estos muebles fue José Sarmiento y Valladares, conde de Moctezuma y de Tula, el cual contó entre sus propiedades con dos biombos de dos haces cada uno, con temas sobre «La conquista de México» y una «Vista de la ciudad» el primero, mientras que en el otro se representaría «La defensa de Viena frente a los turcos» por una

63 La profesora García Saiz ha señalado a los virreyes conde de Galve y conde de Moctezuma como posibles comitentes de estas obras (García Saiz, 1999). Asimismo, Sonia Ocaña defiende la idea de la vinculación entre esta técnica y la identidad criolla (Ocaña, 2008).

64 El cuadro que representa la plaza mayor de México de Cristóbal de Villalpando fue propiedad del conde de Galve y los descendientes del duque de Alburquerque conservan otra pintura sobre México (Martínez del Río, 1994).

65 AHPM, 2320, 21 de septiembre de 1617, 92r-93v.

66 Martínez del Rio, 1994, 133-150. 


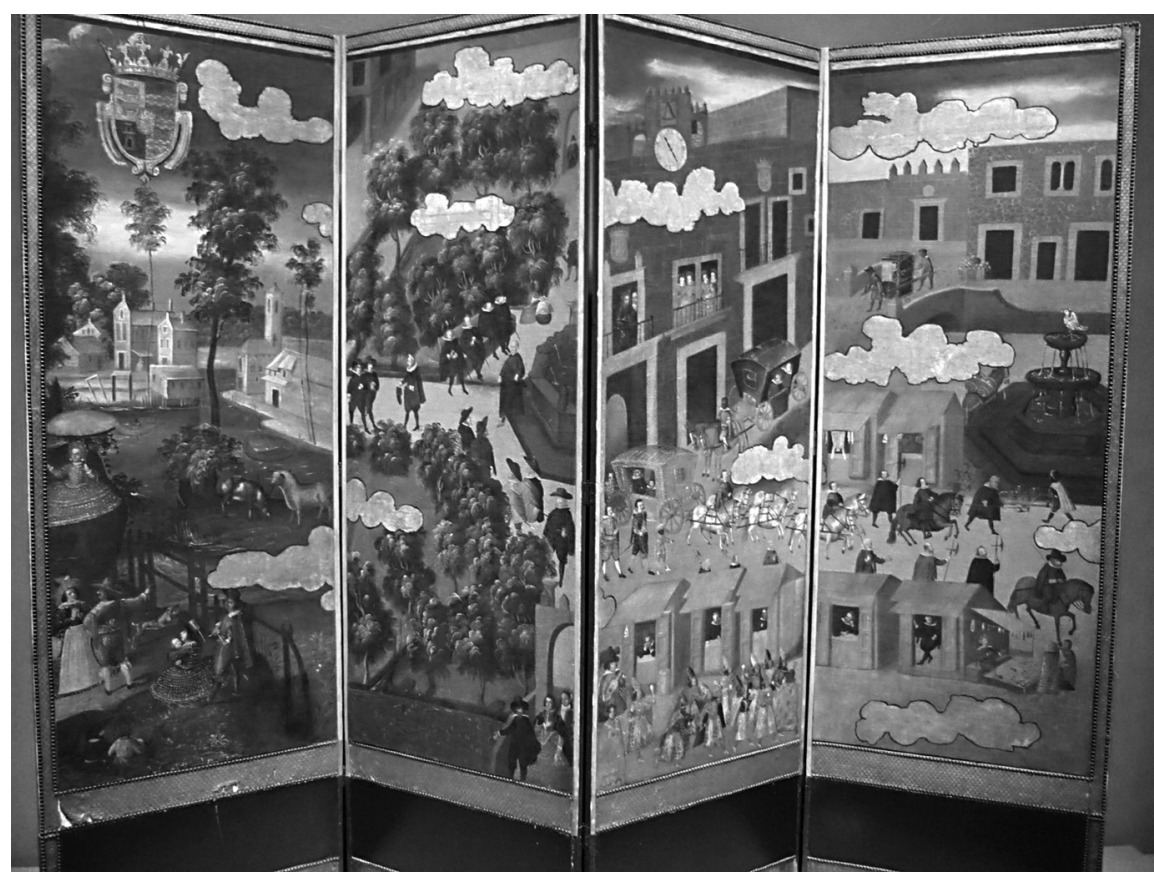

Biombo con «Vista de la Plaza Mayor de la ciudad de México y del paseo de Iztacalco», colección Rivero Lake

cara y «Una escena de caza» en su reverso. Este ejemplar resulta muy interesante si tenemos en cuenta que es uno de los pocos que fue hecho con la técnica del enconchado, típica del virreinato, y que se elaboró en una coyuntura política especialmente sensible como fue la sucesión de Carlos II.

Por último, entre los objetos que se incautaron al virrey Iturrigaray en 1808 se hallaban «siete biombos de diversas calidades y pinturas», mientras que entre los muebles de su propiedad que se registraron en el palacio de Chapultepec aparecía «un biombo de moda con tallas doradas». ${ }^{67}$ Estos bienes, de no haber sido retenidos, también hubieran acabado junto a Iturrigaray en España como prueba de su paso por la capital novohispana.

67 «Inventario de bienes del virrey depuesto Iturrigaray, 22 de septiembre de 1808-17 de mayo de 1809 confiscados por las Reales cajas» en García, 1985, 2, 471. 
Con los gobernadores de Filipinas sucedió algo parecido. Don Fausto de Crusat y Góngora debió de ser un gran aficionado al arte oriental y entre las propiedades que en 1701 le acompañaron a su vuelta a México se encontraban numerosos muebles japoneses, 21 escritorios, 10 de ellos de maque fino; abundante porcelana, abanicos y quimonos chinos; $y$ hasta tres camas de ébano de estilo salomónico hechas en la India. Entre estos objetos llama la atención la presencia de 11 biombos japoneses de diferentes tamaños y materiales (maqué, madre perla, oro y piedra ágata), destacando un conjunto de cuatro biombos de 6 hojas cada uno valorado en 625 pesos. ${ }^{68}$ Por su número y valor puede que muchas de estas piezas fueran transportadas con la idea de venderse al llegar a su nuevo destino, sirviendo como promotor inconsciente de influencias culturales.

En el caso de Perú, también se pudieron utilizar las embarcaciones que debían trasladar a las dignidades eclesiásticas o civiles destinadas al virreinato para transportar mercancías ilegales venidas desde Asia. El viajero italiano Gemelli Careri pudo comprobar cómo en 1697 coincidieron en el puerto de Acapulco la nao de China con el navío que debía conducir al nuevo virrey del Perú, Conde de Cañete, hasta Lima. ${ }^{69}$ Esta situación fue aprovechada por los comerciantes peruanos para transbordar una gran parte de los productos asiáticos de la nao hasta el barco del representante real, seguramente con su complicidad. ${ }^{70}$

Además, entre los inventarios de bienes de los capitanes portugueses y holandeses implicados en el comercio del Pacífico encontramos escritorios y cajas japonesas, lo cual nos pone en relación con el gusto por acumular obras de arte que pudieron desarrollar en sus viajes. No olvidemos que por su situación privilegiada dentro del comercio mundial tuvieron acceso a las mejores piezas y a precios más baratos que los compradores habituales. En Portugal fue común encontrar biombos entre el ajuar doméstico de aquellas personalidades que tuvieron relación con el Estado da India. El alférez mayor Joam de Meneses, por ejemplo, murió cuando volvía a Lisboa desde Goa transportando entre sus pertenencias dos biombos, ${ }^{71}$ el hidalgo García de Mello Torres, que tuvo derecho a un viaje a China, dejó en testamento dos biombos japoneses de cuatro hojas cada uno, mientras que Diego Valente, que fue obispo del Japón, cuando falleció tenía tres

68 AGN, Civil, 114, 1.

69 Gemelli Careri, 2002, 6 y 7.

70 Calderón, 2003, 587.

71 Arquivo Histórico Ultramarino, Conselho Ultramarino, c.16, 3. 
pares de biombos. ${ }^{72}$ Así, Yoshitomo Okamoto mantiene que los mercaderes que frecuentaban Nagasaki «were of course the pioneers in popularizing namban tastes». ${ }^{73} \mathrm{Su}$ objetivo al juntar estos objetos pudo no estar sólo en la mera ostentación sino que es posible que les apeteciese también recordar los lugares por los que habían pasado. Asimismo, en el caso de los ejemplares producidos para la exportación en los que aparecen europeos llegando hasta las costas de Asia, puede que sus dueños quisieran conservar un testimonio de su actividad comercial, origen de su riqueza y de su formación cosmopolita.

Entre los capitanes españoles de Manila podemos observar una costumbre parecida a sus homólogos holandeses y portugueses por acumular objetos orientales. Por ejemplo, entre los bienes embargados en 1720 al maestre de Campo don Esteban Eguiño, quien formase parte de una compañía de comercio que se dedicaba a la compra de objetos asiáticos para reenviarlos en la nao de China hasta Acapulco, encontramos cuatro biombos de papel pintado. ${ }^{74}$ En Nueva España, si bien el gusto por los productos orientales se extendió rápidamente entre el conjunto de la población, este interés fue si cabe más acentuado entre aquellos que tenían o habían tenido algún tipo de relación con el comercio del Pacífico, sirviendo en un principio como introductores y difusores. ${ }^{75}$

Resulta especialmente ilustrativo de la relación directa que se estableció entre aquellos personajes que tenían algún tipo de vinculación con Filipinas y el origen oriental de la mayoría de piezas que componían su ajuar doméstico, el caso del capitán Andrés de Acosta, quien en 1622 mantenía relaciones con las islas e importaba cajones de mercaderías de China. Este comerciante, aparte de tener dos biombos entre sus bienes personales, contaba con un escritorio, un baúl, un escritorillo, un bufete y varias cajas de espejos de Japón, además de tres sobrecamas de la India bordadas de oro

72 Citado por Mendes Pinto, 1993, 20-21.

73 Okamoto, 1993.

74 AGI, Filipinas, 170, 4, 32r y 39r.

75 En el siglo XVII, el capitán Felipe de Navarijo, o la hija del capitán Cristóbal Gomes de la Madriz, Ana María Gomes de la Madriz, disfrutaron de biombos asiáticos en sus casas de la capital (AGN, Civil, 1802, 1 y AGN, Civil, 1863, 19). Mientras que los mercaderes Pedro de Burgos, propietario de una tienda de ropa y telas, o Álvaro de Lorenzana, miembro del Consulado de México, tuvieron varios ejemplares chinos (AGN, Civil, 1835, 6; AGN, Bienes Nacionales, 1294, 1, 1653). Ya en el siglo XVIII, el comerciante Nicolás de Arteaga y el dueño de un cajón en la plaza mayor, Miguel de Ibarburo, también tuvieron varios «rodaestrados de china» (AGN, Bienes Nacionales, 404, 5; AGN, Civil, 323, 1). 
y seda, un pabellón de tafetán, un cajoncillo, quimonos y abanicos de China, e incluso una esclava china de catorce años. ${ }^{76}$ Los objetos incluidos en este inventario de bienes prueban la facilidad y el interés con el que un mercader afincado en Nueva España accedía a todo tipo de mercancías asiáticas. ${ }^{77}$ También entre los funcionarios enriquecidos hubo quien quiso acceder a estas piezas que el comercio internacional ponía a su disposición, como el tesorero de la Casa de la Moneda de la ciudad de México, Luis Moreno de Monroy, que en 1622 declaraba tener entre sus propiedades «un biobo grande y dos pequeños» valorados en 70 pesos $;{ }^{78}$ o la mujer del contador Francisco de Castro y Prado, que en 1694 poseía un «biobo de China con diez tablas». ${ }^{79}$ Ya en la Península, como vimos, los comerciantes sevillanos presentaban una situación muy similar. Entre las pertenencias consignadas al capitán don Martín de la Mata, quien participase del tráfico con Nueva España durante gran parte de la segunda mitad del siglo XVII, encontramos un biombo de estrado de «18 hojas pintadas con la historia de Cortés y Moctezuma». ${ }^{80}$

Por último, en el lado japonés, los mercaderes enriquecidos con el comercio abierto con occidente fueron uno de los mayores grupos consumidores de biombos namban. ${ }^{81}$ En este sentido, algunos autores han señalado cómo las pinturas más antiguas donde aparecen representados los portugueses llegando a Japón evidencian la temática comercial a través del énfasis puesto en la representación de las actividades mercantiles, resaltando la nao de trato portuguesa y los productos que se descargaban. De esta forma, el éxito de estas composiciones en los biombos de la escuela Kano reflejaría el gusto y los intereses de una clase mercantil emergente..$^{82}$

Aparte de lo señalado, otro aspecto importante a tener en cuenta a la hora de estudiar el movimiento de personas y biombos a nivel mundial son las redes tejidas por las órdenes religiosas a través de cuatro continentes. Muchas obras de arte circularon entre Asia, América y Europa de la mano de los frailes mendicantes. Los jesuitas, responsables de la misión en

76 AGN, Civil, 1998, 3.

77 Berenice Ballesteros ha probado el éxito que tuvo durante el siglo XVII el menaje asiático entre los miembros del Consulado de México; los inventarios consultados para el XVIII muestran características similares. Ballesteros, 2008.

78 AGI, México, 263, 131.

79 AGN, Bienes Nacionales, 445, 4.

80 AHPS, oficio 9, libro 1, 187-191, 23 de febrero de 1691.

81 Boxer, 1968, 22.

82 Sato, 2002, 18, 31-34. 
Japón, adquirieron biombos durante su residencia en aquellas islas y los colocaron en sus celdas, como se indica en las «obedencias» de 1612 en las que se prohibía que los misioneros decoraran sus cuartos con este tipo de muebles ${ }^{83}$ Es de suponer que, en sus cambios de residencia, muchos sirvieron de intermediarios en su divulgación por el mundo. Además, para el siglo XVIII hemos documentado biombos en varias haciendas jesuitas de Nueva España. El estudio detenido de las propiedades y encomiendas asociadas a la Iglesia pueden revelar nuevos datos asociados al movimiento de objetos.

\section{Consideraciones finales}

La apertura y consolidación de dos rutas entre Europa y Asia vino incentivada por el desarrollo de una enorme demanda de productos orientales por parte de las sociedades occidentales. El análisis pormenorizado de las fuentes demuestra la importancia que tuvo el tráfico de objetos de lujo dentro del comercio internacional y cómo, entre los muebles más valorados y cotizados, se encontraron los biombos. Su transporte desde China o Japón hasta Portugal y Castilla a través de la India o de América, prueba la existencia de una «primera mundialización» de las relaciones económicas con base en las coronas ibéricas. El largo camino recorrido por los biombos nos revela un conglomerado de conexiones que los imperios, si no las inventaron, sí las propiciaron o estimularon, creando las condiciones para que pudieran llevarse a cabo. Así, el tráfico de esta mercancía permite identificar los intermediarios más destacados del comercio con Manila, destacando portugueses, chinos y japoneses, además de los principales puertos desde donde se importaban: Macao, Cantón y Nagasaki.

Además, la ruta mundial seguida por los biombos nos permite desterrar el eurocentrismo propio de los análisis históricos más tradicionales. La importancia que llegó a adquirir el comercio a través del Galeón de Manila demuestra que Europa no siempre fue la explicación última de todos los fenómenos sino que en ocasiones fueron otras las regiones que llevaron la iniciativa o marcaron el volumen y características de los productos incluidos en los intercambios. Por lo tanto, el tráfico de biombos nos permite redefinir los términos de centro y periferia, ya que, en lo que se refiere a la

83 Boxer, 1974, 215. 
«ruta española» del Pacífico, el centro no fue Europa sino Nueva España, y fue precisamente el Consulado de México quien controló la Nao de China. Siendo esto así, cobran sentido los versos laudatorios de Bernardo de Balbuena quien, en su Grandeza Mexicana, reivindicaba el lugar de este territorio como ombligo del mundo:

En ti se juntan España y China

Italia con Japón, y finalmente

un mundo entero en trato y disciplina. ${ }^{84}$

Ya sea como regalo diplomático o como mercancía de encargo, no es posible entender el éxito de los biombos en el tráfico mundial y su fácil integración a culturas diferentes si no se rompe con la «retórica de la alteridad». De esta forma, resulta necesario hacer hincapié en los puntos en común, las circulaciones de todo tipo y las conexiones entre los distintos lugares, por muy lejanos que parezcan. El comercio entre europeos y asiáticos se hizo en unas condiciones muy diferentes a las que se establecieron con las civilizaciones precolombinas conquistadas, China y Japón fueron valoradas desde occidente como culturas refinadas con las que era posible establecer una relación más o menos de igualdad. El resultado de este equilibrio fue la difusión de los biombos entre los ajuares domésticos de las familias principales de Asia, América y Europa, ejemplo de una cultura material de carácter mundial que compartía determinados valores asociados a la búsqueda de prestigio u ostentación. Este fenómeno integrador propició que, independientemente de que variaran los temas representados en sus hojas, los biombos ocupasen un lugar preeminente en los espacios principales de los palacios de tres continentes.

El nacimiento en el siglo XVII de una producción de biombos en Nueva España y su exportación al resto de América y Europa explican la vitalidad de los procesos propiciados por los intercambios económicos. De igual manera, el desarrollo posterior de otras manufacturas locales en América como las de Perú, Guatemala o Colombia, reflejan la madurez artística que para el siglo XVIII se había alcanzado en el continente. La asimilación y reinterpretación de los biombos dentro de la cultura material americana dio como resultado unas dinámicas artísticas originales que se pueden asociar al gusto e identidad criollos.

84 Balbuena, 2006, 91. 
Por otra parte, la posible producción de biombos por artesanos de origen chino o japonés en Manila nos pone en relación no sólo con el movimiento de mercancías a través de estas rutas sino también con el significativo flujo de personas que se dio entre estos territorios y su influencia en las producciones regionales. Del lado de los europeos, descubrimos un grupo de funcionarios reales y comerciantes que se movieron por los dominios mundiales de la Monarquía Católica divulgando inconscientemente una cultura material nueva que unas veces resultaba simplemente ecléctica y otras sincrética. El estudio de los inventarios de bienes de estos personajes nos acerca la imagen de unos individuos que no sólo buscaron la riqueza inmediata sino que, además, muchos supieron valorar y apreciar las expresiones artísticas de aquellos lugares por los que pasaron. Por lo tanto, los biombos fueron los testigos mudos del movimiento mundial de personas que la gestión política, económica o religiosa de los territorios que componían el Imperio español puso en marcha.

Presentado el 26 de junio de 2011

Aceptado el 1 de febrero de 2012

\section{Bibliografía}

Aguiló, Marí Paz: El mueble en España. Siglos XVI y XVII, Madrid, CSIC, 1993.

Alva Rodríguez, Inmaculada: «La centuria desconocida: el siglo XVII» en Cabrero, Leoncio: Historia general de Filipinas, Madrid, Ediciones de Cultura Hispánica, AECI, 2000, 207-248.

Álvarez Taladriz, José Luís: La pintura japonesa vista por un europeo a principios del siglo XVII, Osaka, Osaka Gaikokugo Daigaku, 1953.

Arte y Saber. La cultura en tiempos de Felipe III y Felipe IV, Valladolid, Ministerio de Educación y Cultura, 1999.

Baena, Alberto: «Nueva España a través de sus biombos», en Navarro Antolín, Fernando (ed.): Orbis incognitus: avisos y legajos del Nuevo Mundo, Huelva, Universidad de Huelva y Asociación Española de Americanistas, 2007, 441-450.

Balbuena, Bernardo de: La grandeza mexicana, México, Porrúa, 2006.

Ballesteros, Berenice: «El menaje asiático de las casas de élite comercial del virreinato novohispano del siglo XVII», Boletín del Archivo General de la Nación, 20, México, 2008, 59-112.

Bonialian, Mariano: «México, epicentro semiinformal del comercio hispanoamericano (1680-1740)», América latina en la historia económica, 35, México, enero-junio de 2011, 7-28. 
Boxer, Charles: Fidalgos in the Far East (1550-1570), Hong Kong, Oxford University Press, 1968.

Boxer, Charles: The Christian Century in Japan, 1549-1650, Berkeley, University of California Press, 1974.

Calderón, Francisco R.: Historia económica de la Nueva España en tiempo de los Austrias, México, Fondo de Cultura Económica, 2003.

Canepa, Teresa: «Obras de arte namban para os mercados japonês, português e holandês» en Welsh, Jorge e Vinhais, Luisa (eds.): Depois dos bárbaros II. Arte Namban para os mercados japonês, português e holandês, Londres, 2008, 14-29.

Castelló, Teresa y Martínez, María Josefa: Biombos mexicanos, México, Instituto Nacional de Antropología e Historia, 1970.

Crespo, María Dolores: Arquitectura doméstica de la Ciudad de los Reyes (15351750), Sevilla, Universidad de Sevilla, 2006.

Curiel, Gustavo: «Los biombos novohispanos: escenografías de poder y transculturación en el ámbito doméstico» en Curiel, Gustavo; Navarrete, Benito y Leroy, Iván: Viento detenido, mitologías e historias en el arte del biombo, México, Ed. Museo de Soumaya, 1999, 9-32.

Curiel, Gustavo: «El efímero caudal de una joven noble. Inventario y aprecio de los bienes de la marquesa Doña Teresa Francisca María de Guadalupe Retes Paz Vera (Ciudad de México, 1695)» en Anales del Museo de América, 8, Madrid, 2000, 65-101.

Chaunu, Pierre: Las Filipinas y el Pacífico de los ibéricos, siglos XVI-XVII-XVIII: estadísticas y atlas, México, Instituto Mexicano de Comercio Exterior, 1976.

Fernández, Gloria: Inventarios reales, Madrid, Museo del Prado y Patrimonio Nacional, 1975.

Fernández Miranda, Fernando: Inventarios reales, Carlos III, Madrid, Patrimonio Nacional, 1988.

Frois, Luis S. J.: Historia de Japam, Wicki, José (ed.), vol. V, Lisboa, Biblioteca Nacional, 1984.

García Sáiz, M. Concepción: «La conquista militar y los enconchados. Las peculiaridades de un patrocinio indiano», en Los pinceles de la historia, México, Consejo Nacional para la Cultura y las Artes/Instituto Nacional de Bellas Artes, 1999, 109-141.

García, Genaro: Documentos históricos mexicanos, México, Instituto Nacional de Estudios Históricos de la Revolución Mexicana, 1985.

Gemelli Carreri, Giovanni F.: Viaje a la Nueva España, México, UNAM, 2002.

Germaná, Gabriela. «El mueble en el Perú en el siglo XVIII: estilos, gustos y costumbres de la élite colonial», Anales del Museo de América, 16, Madrid, 2008, 189-206.

Gil, Juan: La India y el Lejano Oriente en la Sevilla del Siglo de Oro, Sevilla, Ayuntamiento de Sevilla, 2011. 
Gruzinski, Serge: Las cuatro partes del mundo, México, Fondo de Cultura Económica, 2010.

Gutiérrez de Medina, Cristóbal: Viaje de tierra y mar, feliz por mar y tierra, que hizo el excelentísimo marques de Villena, México, UNAM, 1947.

Leroy, Iván: «El Diluvio», en Curiel, Gustavo, Navarrete, Benito y Leroy, Iván: Viento detenido, mitologías e historias en el arte del biombo, México, Ed. Museo de Soumaya, 1999, 119-134.

López Pérez, María del Pilar: «Itinerario entre la realidad y la intimidad. biombos coloniales. pinturas inéditas de la vida diaria virreinal», Credencial Histórica, 105, Bogotá, 1998.

Martínez del Río, María J.: «Permanencias y ausencias de obispos, virreyes e indianos» en García, María Luisa: México en el mundo de las colecciones de arte, 2, UCOL, México, 1994, 3-44.

Martínez del Rio, María J.: «Los biombos en el ámbito doméstico: sus programas moralizadores y didácticos» en Tovar, Rafael; Estrada, Gerardo; Hernández, Roberto y López, Carmen: Juegos de ingenio y agudeza, la pintura emblemática en la Nueva España, México, Museo Nacional del Arte, Ed. Equilibrista, 1994, 133-150.

Mendes Pinto, María Helena: Biombos Namban, Lisboa, Instituto portugués de Museos, 1993.

Morga, Antonio de: Sucesos de las Islas Filipinas, México, Fondo de Cultura Económica, 2007.

Ocaña, Sonia I: «Marcos “enconchados": autonomía y apropiación de formas japonesas en la pintura novohispana», Anales del Instituto de Investigaciones Estéticas, 92, México, 2008, 107-153.

Okamoto, Yoshitomo: The namban art of Japan, Tokio, Eweatherhill/Heibonsha, 1993.

Recopilación de leyes de los reinos de Indias, Madrid, Cultura Hispánica, 1973.

Romero, Manuel: Una casa del siglo XVIII, México, Imprenta Universitaria, 1957.

Russell Wood, A. J. R.: The portuguese empire: a world on the move, Baltimore, The John Hopkins University Press, 1998.

Sanabrais, Sofía: «The Biombo or folding screen in colonial México» en Pierce, Donna and Otsuka, Ronald: Asia \& Spanish America, trans-pacific artistic and cultural exchange, 1500-1850, Denver, Simposium series, Denver Art Museum, 2006, 69-106.

Sandoval, Martha Inés: El biombo del volador, una boda de indios, escenario para dos categorías de naturales y dos posturas encontradas, México, Tesis UNAM, abril de 2007.

Sanz, María Jesús y Dabrio, María Teresa: «Inventarios artísticos sevillanos del s. XVIII. Relación de obras artísticas» en Archivo Hispalense, LVII, Sevilla, 1974, 89-150. 
Sato, Yashumiro: «Sings and meanings in Naban screens» en Studies in Art History, 18, Tokyo, 2002, 31-34.

Satow, Ernest (ed.): The voyage of Captain John Saris to Japan 1613, Londres, Hakluyt Society, 1900 (reimpresión, Nueva York, 1967).

Sebastián, Santiago: Iconografía e iconología del arte novohispano, México, Azabache, 1992.

Subrahmanyam, Sanjay: «Connected Histories: Notes towards a Reconfiguration of Early Modern Eurasia» en Modern Asian Studies, 31, 3, Cambridge, July, 1997, 735-762.

Subrahmanyam, Sanjay: The Portuguese empire in Asia, 1500-1700: a political and economic history, London-New York, Longman, 1993.

Viera, Juan de: Compendiosa narración de la ciudad de México, México, Guarania, 1952.

Vivero, Rodrigo de: Relación del Japón, Madrid, Editorial del Cardo, 2003.

Yuste, Carmen: «Los precios de las mercancías asiáticas en el siglo XVIII» en García, Virginia (ed.): Los precios de alimentos y manufacturas novohispanos, México, Comité Mexicano de Ciencias Históricas, 1995, 231-264.

Yuste, Carmen: Emporios transpacíficos: comerciantes mexicanos en Manila, 1710-1815, México, UNAM, 2007. 